\title{
Seismic analysis of Portuguese adobe buildings
}

\author{
L. Sarchi \& R. Monteiro \\ Scuola Universitaria Superiore IUSS, Pavia, Italy \\ H. Varum \\ Civil Engineering Department, Faculty of Engineering, University of Porto, Porto, Portugal
}

\begin{abstract}
Considering the likely unfavorable behavior under seismic action of adobe construction, the present work aims at providing a seismic fragility characterization of two adobe Portuguese traditional buildings, using numerical models calibrated over experimental results. Two case-study buildings in the region of Aveiro, were numerically modeled to estimate their structural behavior under seismic loading. Adobe material properties were calibrated based on the experimental results of a cyclic in-plane test of a fullscale I-shaped adobe wall. The method chosen to characterize adobe masonry and model its nonlinear behavior followed a total strain crack-based macro-modelling (TSCM) approach, whereas pushover analysis was carried out to reproduce the pseudo-static experimental test in order to allow a refined calibration of adobe masonry mechanical properties. Fragility functions were then derived, based on the above-mentioned numerical models, using nonlinear static analysis, bringing further insight on the seismic fragility of traditional Portuguese adobe dwellings.
\end{abstract}

\section{INTRODUCTION}

Adobe masonry is one of the oldest building techniques; the earthen bricks are produced manually throwing wet earth into formwork and then let airdry. The combination of good thermal, hygrometric and acoustic properties of earth together with its low cost and easy availability makes it one of the most diffuse building technique, such that around $30 \%$ of world population is estimated to live in earthen houses (Houben \& Guillard, 1994). On the other hand, when it comes to adobe masonry's seismic behavior, its characteristics may result in a possible unfavorable behavior due to the low-tension strength and the mechanical properties of dry earth (Blondet, Vargas, Torrealva, Tarque, \& Velazquez, 2006). As such, and given that the distribution of earthen construction around the world matches fairly the medium-to-high seismic prone areas (De Sensi, 2003), the structural behavior of this construction type may represent a serious threat in terms of social and economic losses in case of an earthquake. Therefore, the principal scope of this research is to calibrate material properties of adobe masonry in order to assess the seismic vulnerability of two adobe dwellings through fragility functions, with the main advantage of precisely using experimental data, in order to achieve a better characterization of adobe masonry, focusing on the particular case of Portuguese construction of this sort.

\section{CALIBRATION OF ADOBE MASONRY PROPERTIES}

\subsection{Experimental testing}

The experimental data used in the present study is taken from a series of experimental tests conducted in the Laboratory of the Civil Engineering Department of the University of Aveiro, Portugal.

Specifically Varum et al. (Varum, Figueiredo, Silveira, Martins, \& Costa, 2011) carried out an inplane cyclic loading test on a full-scale I-shaped adobe wall to analyze the cyclic response of the wall, the damage pattern evolution and to assess an effective retrofitting measure.

Furthermore, more recently ten full-scale adobe wallets were constructed in the laboratory to assess the adobe masonry material properties. Stress-strain relationship, strength, deformation, stiffness and damage pattern of the adobe masonry were derived from the specimens testing. Compressive strength, shear strength, modulus of elasticity and Poisson's ratio were evaluated through simple compression and diagonal compression tests on the adobe wallets (Silveira, Varum, Costa, \& Carvalho, 2015). 


\subsection{Numerical modelling}

In line with the results and characteristics of the studies encountered in the dedicated literature review, a macro-modelling approach was chosen to represent adobe masonry and a total strain crack model (TSCM) was selected to characterize its behavior.

The tests were reproduced using the software MidasFEA (CPS-FEA, 2015) and the wall was modelled using three 4-node rectangular shell elements. To fully reproduce the test set-up (Varum et al., 2011), a horizontal displacement of $1.25 \mathrm{~mm}$ was applied at $2.5 \mathrm{~m}$ height on one of the transverse walls, to simulate the displacement corresponding to the maximum drift of $0.05 \%$ reached during the cyclic test. The calibration is then performed comparing the numerical pushover curve with the experimental envelope of the cyclic force-displacement curve. For the linear range, displacement and frequency were chosen as benchmark parameters to calibrate the elastic modulus (E), while a more refined calibration of the nonlinear material properties, such as tensile strength, tensile fracture energy and compressive strength, was performed by varying each parameter at a time and choosing the value that best fits the test pushover curve results, see Figure 1.

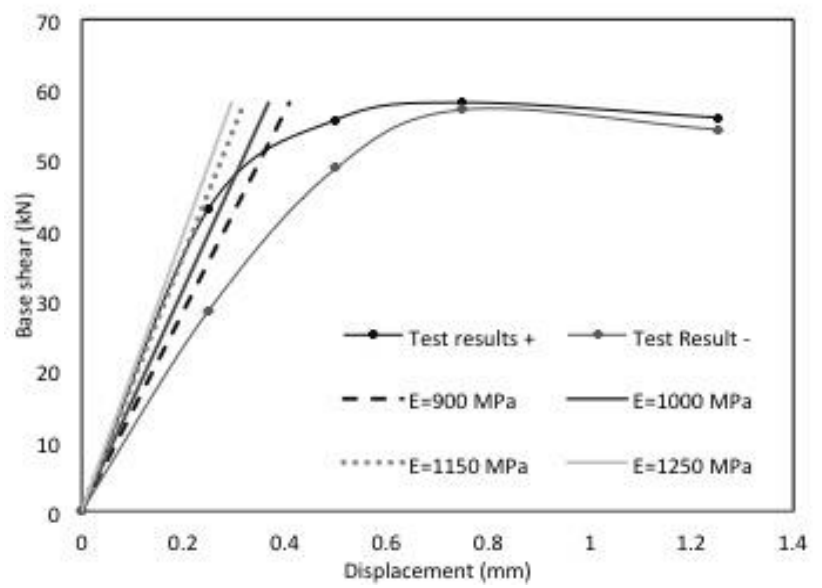

(a)

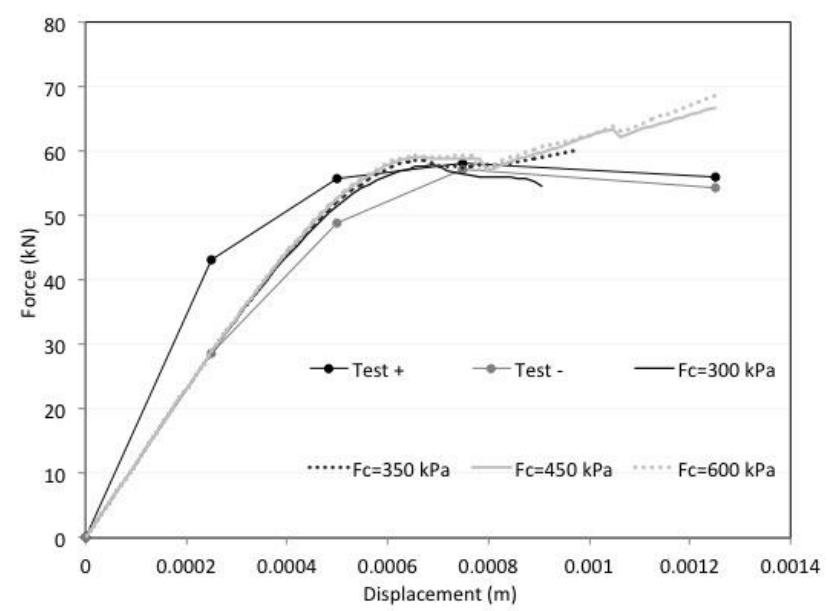

(b)

Figure 1. Calibration of adobe material properties for (a) elastic range and (b) nonlinear range.
Globally, the total-strain crack model seems to fit the analysis of adobe masonry based on a general agreement between experimental and numerical results: stress and cracks develop diagonally from the point where the load is applied and the maximum value of the principal stress starts at the corner and then develops along the wall. Finally, the numerical pushover curves match the experimental envelope of the force-displacement curves, so that the assumption of adobe masonry as homogeneous material appears appropriate.

\section{CASE STUDY}

In Portugal in the 19th and early 20th centuries, adobe masonry was widely used, indeed, in the city of Aveiro it is estimated that approximately $40 \%$ of the buildings are made of adobe (Silveira, Varum, Costa, \& Lima, 2013). This building typology is usually regular in plan and height, predominantly with one or two stories.

As such, the buildings selected as case study are located in the municipality of Murtosa, in the Aveiro district. The two buildings, designated as House 25 and House 16 (depicted in Figure 2), are both twostory residential buildings, from early 1900 s, featuring external walls made in adobe and internal walls made of a different and lighter material, tabique, a typical Portuguese timber structure filled and plastered with earth based materials. The houses show pitched tiles roof.

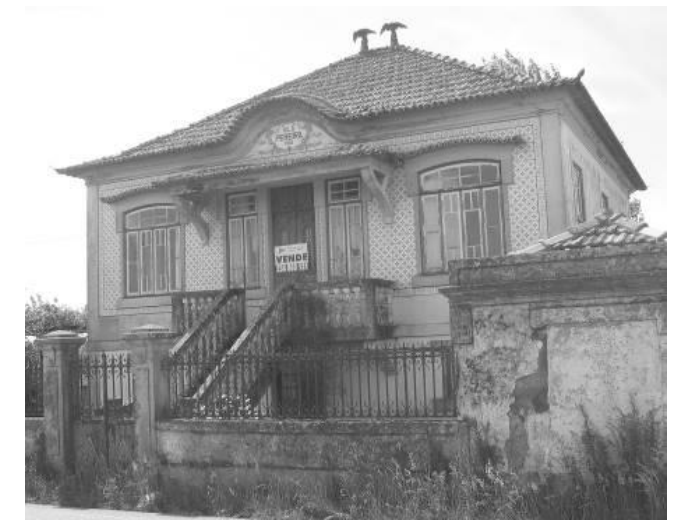

(a)

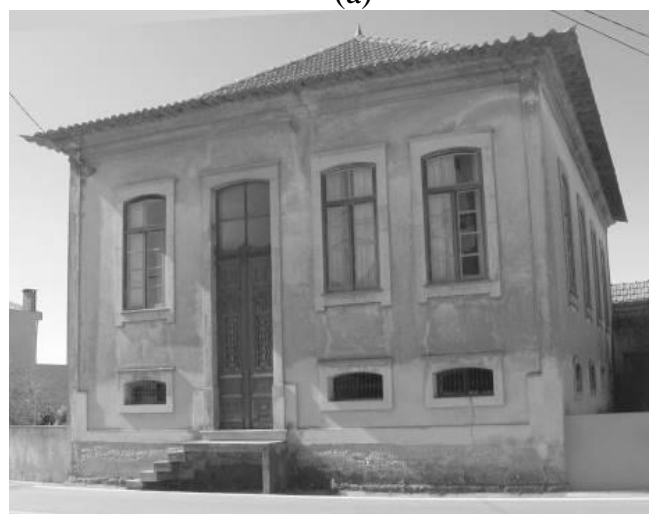

(b)

Figure 2. Case study buildings: (a) House 25 and (b) House 16. 
All the structural elements of the FEM models of the buildings, with exception of the floors, are modeled with shell elements, using a 4-node tetrahedral $0.3 \times 0.3 \mathrm{~m}$ mesh. Floors are modeled with two cross beams and rigid links tie external walls with floors and internal walls.

The numerical analysis of the two buildings aims at understanding the resisting mechanisms under seismic loading, performing a nonlinear static (pushover) analysis. Seismic load is simulated as a static horizontal force applied proportionally to the mass, ranging from $0.08 \mathrm{~g}$ to $0.8 \mathrm{~g}$, in both principal directions $( \pm X$ and $\pm Y$ ). Loads were applied in two phases, first the gravity loads and following the horizontal forces.

Although less accurate than nonlinear dynamic analysis, nonlinear static analysis still allows assessing the structural behavior of the building under horizontal loading taking into account the material nonlinearity. The control points for displacement monitoring were identified at the top of the building.

\subsection{Structural analysis}

In order to assess the influence and importance of the different structural elements on the global seismic behavior of the buildings, different configurations were run and compared in terms of capacity curves. Such short parametric study analyzed the buildings' original configuration (0), and few variants eliminating the internal walls (NW), the floors (NF) and both internal walls and floors (NWF). The corresponding layouts are illustrated in Figure 3.
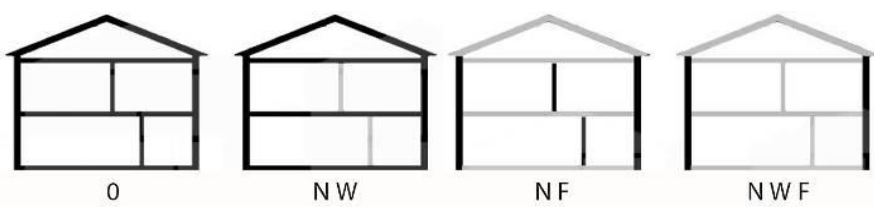

Figure 3. Structural analysis configuration

The capacity curves resulting from the analyses of the configurations are illustrated in

Figure 4 for both axes and directions (positive and negative). It is evident that geometrical and construction characteristics have a significant effect in the seismic response of the building. As such, although apparently regular in plan, the stiffness of the buildings changes according to the direction of application of the load. A potential reduction of the building capacity is in fact linked to uneven distribution of resisting elements and lack of symmetry in one or both orthogonal directions.

As expected, the contribution of internal structural elements, significantly affects the response of the building, being essential to distribute the loads and contributing strongly to its global horizontal stiffness, with contribution of the internal walls (NW) being predominant for house 25 , and floors (NF) for house 16.

In both buildings, the scenario with just external adobe walls (NFW) is not able to sustain a horizontal load beyond $0.1 \mathrm{~g}$, since the external partitions would act as free standing walls, deforming significantly for low intensity loading and then collapsing.

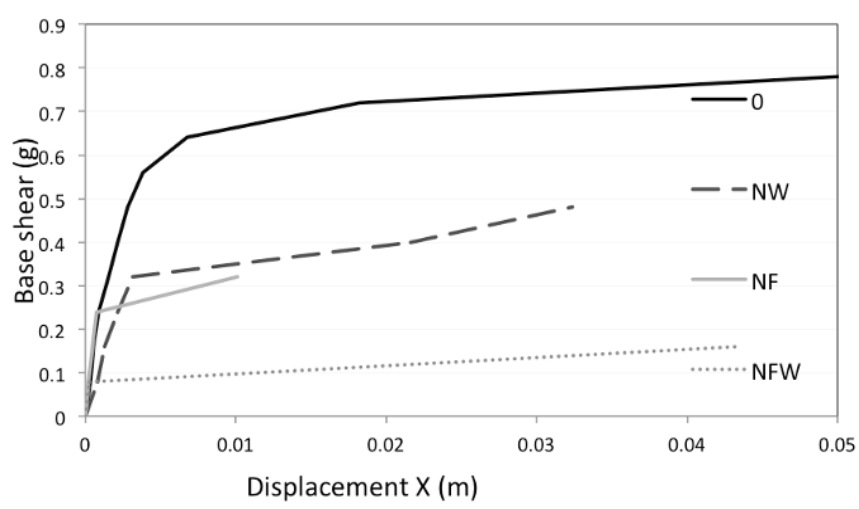

(a)

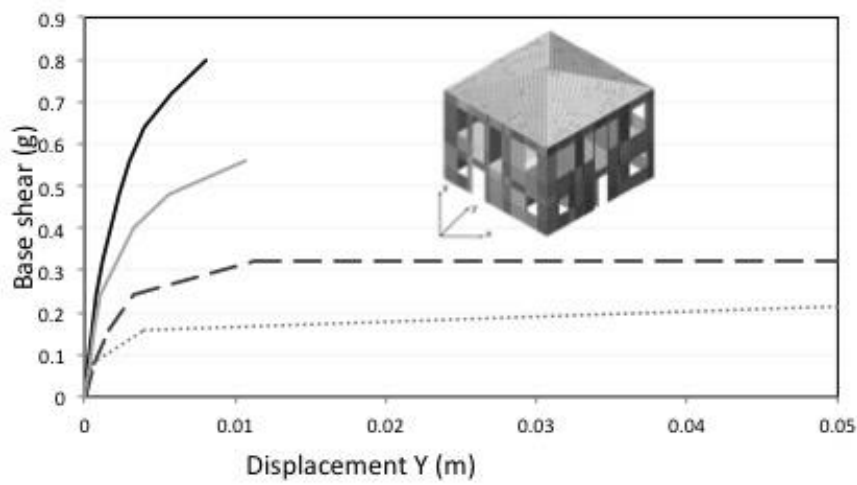

(b)

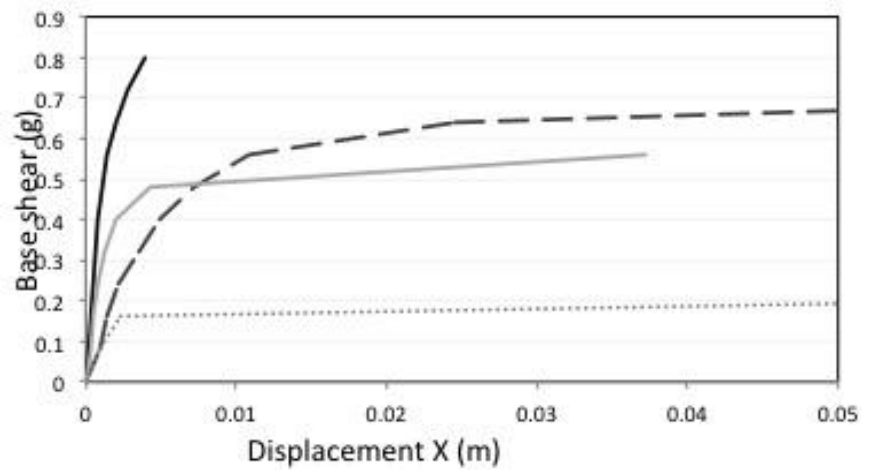

(c)

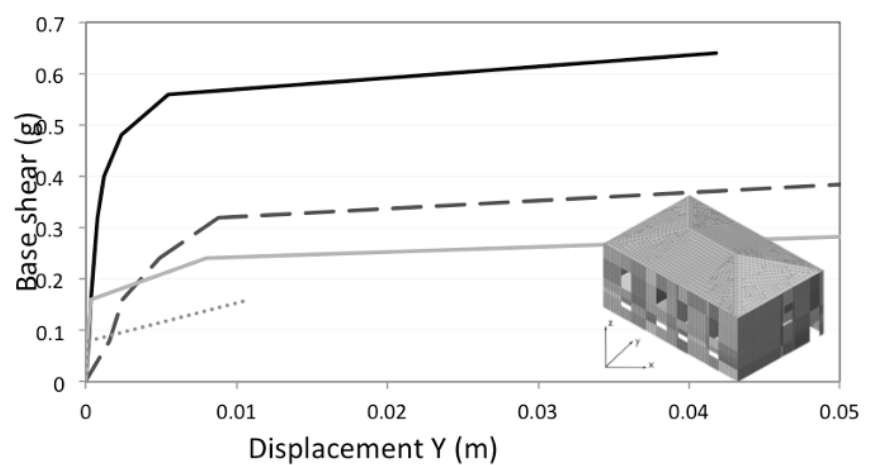

(d)

Figure 4. Capacity curves: House 25 along (a) X and (b) Y direction; House 16 along (c) $\mathrm{X}$ and (d) Y direction. 


\subsection{Damage and retrofitting analysis}

In order to represent the typical damaged conditions of the connections between external walls and the other structural elements, given the poor state of maintenance resulted from the survey on the state of conservation of the buildings of the city of Aveiro (Silveira et al., 2013), a brief analysis of damage scenarios and corresponding retrofitting measures is carried out. Four configurations were chosen: undamaged scenario (0), disconnection of external walls with internal elements and roof (DFWR), disconnection with just floor and walls (DFW) and retrofitted scenario (R), as illustrated in Figure 5.

In the FEM model, this is achieved by disconnecting the links of floors and internal walls with external walls, subsequently, retrofitting measures are modeled through the introduction of tie rods at every floor level (R).

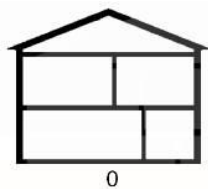

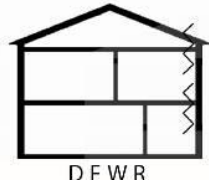

DFWR

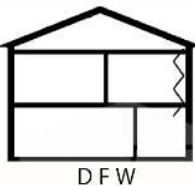

DFW

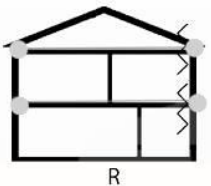

Figure 5. Damage-Retrofit analysis configurations

As expected, the building capacity is strongly reduced due to the disconnection of an external wall with the internal structural elements (floors and walls); collapse takes place for values of acceleration in the range $0.1-0.2 \mathrm{~g}$. The introduction of tie rods for retrofitting purposes $(\mathrm{R})$ compensates the damage simulated on the building, increasing its capacity up to more than twice the value for the corresponding damaged scenario, as evidenced in Figure 6.

\section{FRAGILITY ANALYSIS}

The second step of the present study aims at having an insight on the level of seismic risk these buildings may be subjected to; the physical vulnerability of each of the two case-study buildings is hence characterized through fragility curves.

\subsection{Overview}

Buildings physical vulnerability is typically defined through fragility curves, which represent the relationship between the measure of intensity of a seismic event and the vulnerability of the structure. They indicate the probability of exceedance of a defined limit state (LS), correlated with damage or loss, as function of a given intensity measure of the earthquake (IM).

Literature review on the fragility analysis of earthen construction does not show a real common approach about LS for this category of buildings.
Therefore on each capacity curve, points representing clear changes in the material behavior are chosen as engineering demand parameter (EDP) for the quantification of the building damage. Yielding point, threshold of the linear elastic range, and ultimate point, correspondent to assumed collapse, are identified on both curves.

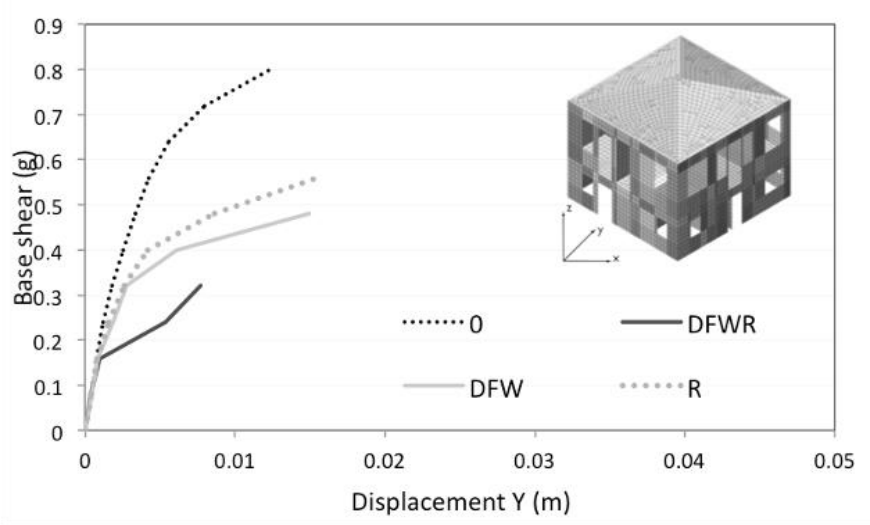

(a)

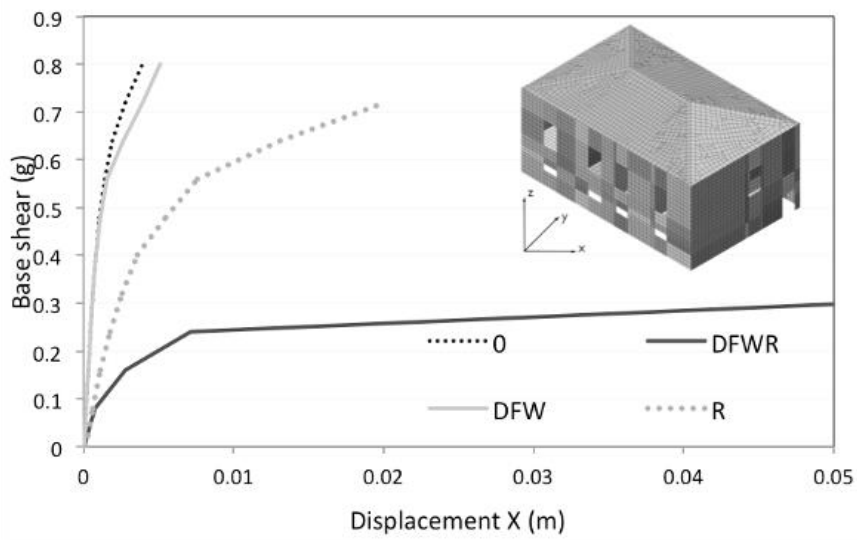

(b)

Figure 6. Damage-retrofit capacity curves: (a) House 25 along Y and (b) House 16 along $\mathrm{X}$ direction.

For what concerns the ground motion input, ground motion records, representing the local hazard and necessary for the nonlinear fragility analyses, were collected in terms of peak ground acceleration (PGA), soil type, epicentral distance and magnitude.

REXEL software (Iervolino, Galasso, \& Cosenza, 2010), a code-based real record selector for seismic analysis of structures, is used in selecting real records waveforms. From the Selected Input Motions for Displacement-Based Assessment and Design (SIMBAD) database, the software searches for a set of seven accelerograms compatible on average to a reference design spectrum, previously created according to Eurocode 8. $\mathrm{a}_{\mathrm{g}}$ is defined according to the national annex values; site class selected is D, 'deposit of loose-to-medium cohesionless soil - with or without some soft cohesive layers - or of predominantly soft-to-firm cohesive soil', as Aveiro region has been recorded to have soft soil (Silveira et al., 2015). 


\subsection{Development of fragility curves}

Procedures to obtain fragility functions involve a certain degree of uncertainty related to the number of records, modeling approximations and availability of data. For this study, analytical approach has been chosen among the others; fragility functions are hence derived using vulnerability assessment algorithm with direct physical meaning. Curves are built from data obtained from simulation of earthquakes intensities on structural models of the asset analyzed. Although it may be limited by modeling capabilities and computational effort of the analyses, it provides insight and data on buildings that have not yet experienced strong motions, which is not possible with empirical models.

Nonlinear dynamic analysis is typically considered more accurate in predicting the structural response of buildings, however pushover-based nonlinear static procedure, N2 method, is employed to evaluate the seismic behavior of the two buildings, given that it has been shown to provide accurate outputs, close to dynamic results (Pinho, Marques, Monteiro, Casarotti, \& Delgado, 2013) and due to the complexity of the model and the time constraints.

Seven performance points are consequently identified for each of the ten intensity measure levels analyzed and then compared to the damage limit state thresholds, to derive the probability of exceedance, once damage states, in terms of target displacements, have been defined for different PGAs. Lognormal cumulative distribution function is then used to characterize fragility functions, according to Equation 1.

$$
P(C \mid P G A=x)=(\underline{\ln x})
$$

$\mathrm{P}$ is the probability of collapse given a ground motion of $\mathrm{PGA}=\mathrm{x}$, and $\Phi$ is the normal cumulative distribution function with $\mu$ and $\beta$ as mean and standard deviation of $\ln$ (PGA) respectively.

To properly calibrate Equation 1, the estimation of $\mu$ and $\beta$ lognormal parameters is performed using the maximum likelihood method as fitting technique to the different points representing the probability of exceedance per IM and LS, according to Baker (Baker, 2015).

Finally, for each limit state, lognormal distribution as function of PGA is then employed to define the fragility curves. Fragility curves obtained for the case-study buildings are shown in

Figure 7, following the described procedure.

For a PGA of approximately $0.1 \mathrm{~g}$, corresponding to a return period of 475 years, the building $\mathrm{H} 25$ has nearly $40 \%$ of reaching the ultimate limit state, whereas global yielding is expected for a PGA around $0.2 \mathrm{~g}$ or $0.3 \mathrm{~g}$. For values of PGA greater than
$0.6 \mathrm{~g}$, the building is expected to collapse. On the other hand, the building H16 seems less vulnerable, according to the fragility results. In fact, less than $20 \%$ probability of collapse, half of the value of House 25, corresponds to the reference PGA of $0.1 \mathrm{~g}$, and the ultimate limit state is expected to occur for values of PGA greater than $0.75 \mathrm{~g}$.

The geometrical configuration may be the reason of the difference in the results of these somewhat similar buildings, given that House 16 is more irregular in plan than House 25.

Uncertainty related to ground motion and modeling affects the fragility curves, resulting in higher values of response capacity for the buildings, when subjected to seismic loading.

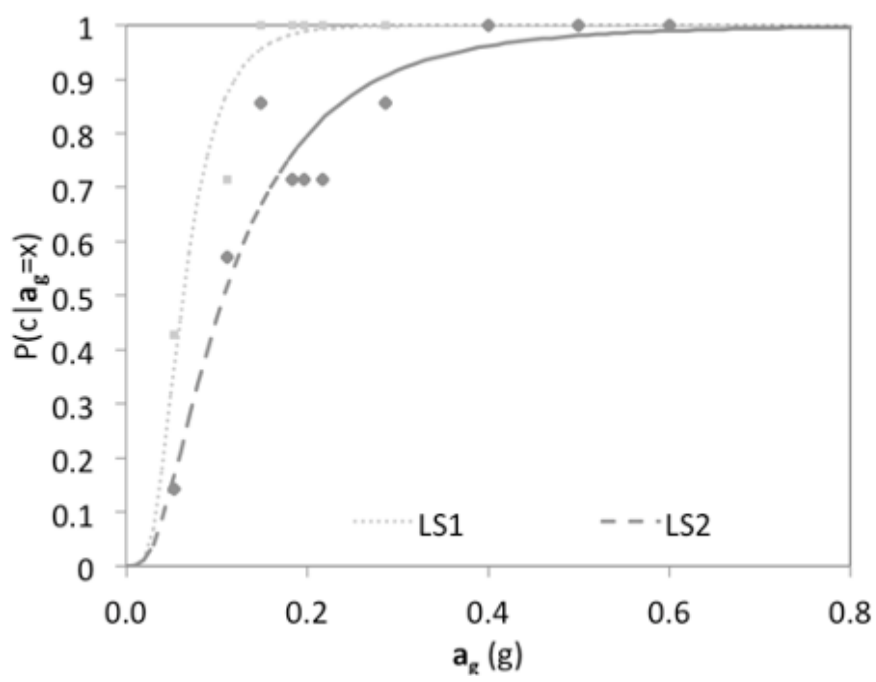

(a)

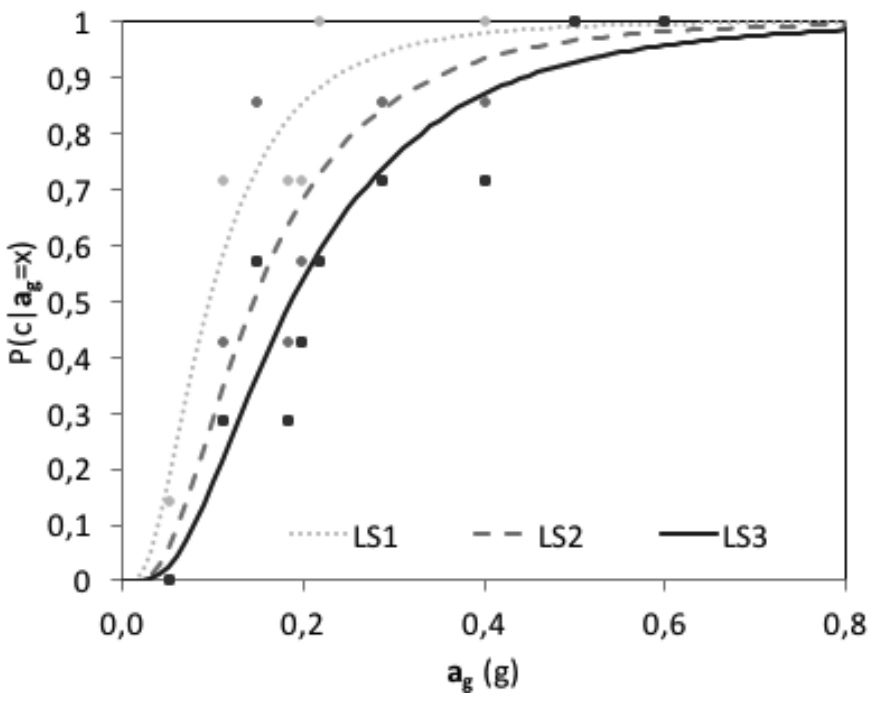

(b)

Figure 7: Fragility curves: (a) House 25 and (b) House 16.

A reduced number of ground motion records has been chosen for reasons of computational onus of the models, while a higher number of records employed would have led to a less discrete distribution of the probability points to which the lognormal distributions are fitted. Modelling approximations play a significant role too, since by assuming the connec- 
tions between orthogonal walls as perfect, the typical weaknesses and damaged condition of such (Ortega, Vasconcelos, Lourenço, Rodrigues, \& Varum, 2015) are not represented. Strong connections are in fact not realistic for this type of buildings, which often experience out-of-plane failure mechanisms when subjected to seismic action.

\section{CONCLUSIONS}

The presented study aims at providing a seismic fragility characterization of two adobe Portuguese traditional buildings, using numerical models calibrated over experimental results.

Since the modeling of adobe masonry parameters features relevant uncertainty given the nature of such composite material, incorporating laboratory results of an I-shaped adobe wall, is meant to increase the accurateness of the numerical model for the adobe buildings.

Given that the experimental and numerical data showed a global agreement, the constitutive model used, TSCM, coupled with macro-modelling approach, results effective in characterizing adobe masonry's nonlinear behavior.

Probability of attainment of the ultimate limit state is hence estimated around $0.5 \mathrm{~g}$, denoting also a generally highly stiff behavior leading to brittle collapse. It has to be considered that uncertainty in the soil composition and numerical modeling approximations affect this result; the assumption of perfectly connected elements, disregarding possible out-ofplane failure, leads to a relatively high 'capacity'.

As such, further developments that may improve the quality of the fragility curves herein produced should focus on:

- Complete reproduction of the experimental test carried out on the I-shaped wall, by performing cyclic analysis on the numerical model;

- Realistic representation of wall-to-wall and damaged connections, assumed as ideal in this study, in order to effectively analyse possible retrofitting measure;

- Nonlinear dynamic analysis to validate the fragility analysis results, given the inherent simplified nature of nonlinear static procedures.

Nevertheless, the presented results can be employed and compared in future risk assessment studies of regions with similar typology of building portfolios. Such information is important to evaluate the seismic vulnerability of such buildings, in order to develop mitigation and retrofitting measures aiming at reducing the loss of life and properties associated to the collapse of this type of construction during earthquakes.

\section{REFERENCES}

Baker, J. W. (2015). Efficient analytical fragility function fitting using dynamic structural analysis. Earthquake $\begin{array}{lll}\text { Spectra, } & 31(1), & 579-599 .\end{array}$ http://doi.org/10.1193/021113EQS025M

Blondet, M., Vargas, J., Torrealva, D., Tarque, N., \& Velazquez, J. (2006). Seismic reinforcement of adobe houses using external polymer mesh. In Proceeding of the First European Conference on Earthquake Engineering and Seismology. Switzerland.

CPS-FEA. (2015). Analysis and Algorithm Manual. Midas FEA Advanced Nonlinear and Detail Analysis Program.

De Sensi, B. (2003). Terracruda, la diffusione dell'architettura.

Houben, H., \& Guillard, H. (1994). Earth Construction: A Comprehensive Guide. London: Intermediate Technology Publications.

Iervolino, I., Galasso, C., \& Cosenza, E. (2010). REXEL: Computer aided record selection for code-based seismic structural analysis. Bulletin of Earthquake Engineering, 8(2), 339-362. http://doi.org/10.1007/s10518-009-9146-1

Ortega, J., Vasconcelos, G., Lourenço, P. B., Rodrigues, H., \& Varum, H. (2015). Seismic behaviour assessment of vernacular isolated buildings. In Seismic Retrofitting: Learning from Vernacular Architecture (pp. 203-212). CRC Press.

Pinho, R., Marques, M., Monteiro, R., Casarotti, C., \& Delgado, R. (2013). Evaluation of nonlinear static procedures in the assessment of building frames. Earthquake Spectra, 29(4), 1459-1476. http://doi.org/10.1193/100910EQS169M

Silveira, D., Varum, H., Costa, A., \& Carvalho, J. (2015). Mechanical Properties and Behavior of Traditional Adobe Wall Panels of the Aveiro District. Journal of Materials in Civil Engineering (ASCE), 27(9), 1-14. http://doi.org/10.1061/(ASCE)MT.1943-5533.0001194

Silveira, D., Varum, H., Costa, A., \& Lima, E. (2013). Survey and characterization of the adobe built park in Aveiro city. In Proceedings of 6th seminar of earthen architecture in Portugal and 9th Ibero-American Seminar of earth architecture and construction (pp. 102-108). Coimbra, Portugal: Centre for Archaeological Studies of the Universities of Coimbra and Porto.

Varum, H., Figueiredo, A., Silveira, D., Martins, T., \& Costa, A. (2011). Investigaciones realizadas en la Universidad de Aveiro sobre caracterizaciòn mecànica de las construcciones existentes en adobe en Portugal y propuestas de rehabilitaciòn $\mathrm{y}$ refuerzo. Resultados alcanzados. Informes de La Construcción, 63(523), 127-142. http://doi.org/10.3989/ic.10.016. 